\title{
A utilização do Formulários Google como ferramenta de avaliação no processo de ensino e aprendizagem em tempos de pandemia de Covid-19: Um estudo em uma escola de educação básica
}

The use of the Google Forms as an assessment tool in the teaching and learning process in times of the Covid-19 pandemic: A study in a basic education school

El uso de Google Forms como herramienta de evaluación en el proceso de enseñanza y aprendizaje en tiempos de la pandemia Covid-19: Un estudio en una escuela de educación básica

Gustavo Nogueira Dias ORCID: https://orcid.org/0000-0003-1315-9443 Colégio Federal Tenente Rêgo Barros, Brasil

E-mail: gustavonogueiradias@gmail.com Pedro Roberto Sousa da Silva ORCID: https://orcid.org/0000-0003-1780-5705 Universidade Federal do Pará, Brasil E-mail: prof.pedromat@hotmail.com

Vanessa Mayara Souza Pamplona ORCID: https://orcid.org/0000-0002-2461-2103 Universidade Federal Rural da Amazônia, Brasil E-mail: vanessamayara2@gmail.com Jamille Carla Oliveira Araújo ORCID: https://orcid.org/0000-0002-2273-2347 Universidade Rural da Amazônia, Brasil E-mail: jamillecarla@gmail.com

Eldilene da Silva Barbosa ORCID: https://orcid.org/0000-0002-9980-2286 Universidade Federal Rural da Amazônia, Brasil E-mail: eldilene.barbosa@gmail.com

Fabricio da Silva Lobato

ORCID: https://orcid.org/0000-0002-8240-8039 Universidade do Estado do Pará, Brasil

E-mail: fabriciolobatomat15@hotmail.com

José Carlos Barros de Souza Júnior ORCID: https://orcid.org/0000-0003-4465-8237

Colégio Federal Tenente Rêgo Barros, Brasil E-mail: barrosctrb@gmail.com

Washington Luiz Pedrosa da Silva Junior ORCID: https://orcid.org/0000-0002-1413-0047 Colégio Federal Tenente Rêgo Barros, Brasil E-mail: jwl_pedrosa@hotmail.com

Gilberto Emanoel Reis Vogado ORCID: https://orcid.org/0000-0003-4763-4767 Universidade do Estado do Pará, Brasil E-mail: gvogado@globo.com

Wagner Davy Lucas Barreto ORCID: https://orcid.org/0000-0002-0675-9005

Colégio Federal Tenente Rêgo Barros, Brasil E-mail: profwlucas@yahoo.com.br

Ana Paula Ignácio Pontes Leal ORCID: https://orcid.org/0000-0002-8733-0066 Universidade Federal Rural da Amazônia, Brasil E-mail: paulaignacio@ hotmail.com

Ademir Ferreira Silva Junior ORCID: https://orcid.org/0000-0001-9121-1206 Universidade Federal do Pará, Brasil E-mail: ademirjunior@ufpa.br Gerson Pompeu Pinto 


\begin{abstract}
Resumo
A pesquisa: A utilização do Formulários Google como ferramenta de avaliação no processo de ensino e aprendizagem em tempos de pandemia de Covid-19, mostrou um estudo descritivo, transversal realizado com alunos do ensino médio de uma escola pública, da cidade de Belém do Pará, frente à utilização do Google forms, como instrumento de avaliação realizado do período de 01 de abril de 2020 até 15 de janeiro de 2021. Observou-se um significativo aumento da utilização das ferramentas tecnológicas utilizadas na educação a fim de suprir o fomento educacional e dar suporte aos estabelecimentos de instrução, em todas as esferas de ensinos. A proposta de utilização do Google Forms como instrumento avaliativo, tornou-se uma ferramenta indispensável, porém algumas restrições foram encontradas. O objetivo do presente estudo é descrever a utilização da ferramenta google forms como instrumento de avaliação com alunos da educação básica em tempos de pandemia da covid-19. Foi observado problemas que afetam o desenvolvimento educacional, como saúde mental e a desigualdade pela falta de acesso aos meios tecnológicos necessários a manutenção da educação além da vulnerabilidade social enfrentada por inúmeros alunos.
\end{abstract}

Palavras-chave: Ferramentas tecnológicas; Google forms; Saúde mental; Vulnerabilidade social.

\begin{abstract}
The research: The use of Google Forms as an assessment tool in the teaching and learning process in times of Covid19 pandemic, showed a descriptive, cross-sectional study carried out with high school students from a public school in the city of Belém do Pará, in view of the use of Google forms, as an assessment tool carried out from April 1, 2020 to January 15, 2021. There was a significant increase in the use of technological tools used in education in order to supply educational and support educational establishments in all spheres of education. The proposal to use Google Forms as an evaluation tool has become an indispensable tool, but some restrictions have been found. The objective of the present study is to describe the use of the google forms tool as an assessment tool with students of basic education in times of pandemic of the covid-19. Problems were observed that affect educational development, such as mental health and inequality due to the lack of access to the technological means necessary to maintain education in addition to the social vulnerability faced by countless students.
\end{abstract}

Keywords: Technological tools; Google forms; Mental health; Social vulnerability.

\title{
Resumen
}

La investigación: El uso de Google Forms como herramienta de evaluación en el proceso de enseñanza y aprendizaje en tiempos de la pandemia Covid-19, mostró un estudio descriptivo, transversal realizado con estudiantes de secundaria de una escuela pública de la ciudad de Belém do Pará, en vista del uso de formularios de Google, como herramienta de evaluación realizada del 1 de abril de 2020 al 15 de enero de 2021. Hubo un aumento significativo en el uso de herramientas tecnológicas utilizadas en educación con el fin de brindar servicios educativos y de apoyo educativo. establecimientos en todos los ámbitos de la educación. La propuesta de utilizar Google Forms como herramienta de evaluación se ha convertido en una herramienta indispensable, pero se han encontrado algunas restricciones. El objetivo del presente estudio es describir el uso de la herramienta de formularios de google como herramienta de evaluación con estudiantes de educación básica en tiempos de pandemia del covid-19. Se observaron problemas que afectan el desarrollo educativo, como la salud mental y la desigualdad por la falta de acceso a los medios tecnológicos necesarios para mantener la educación, además de la vulnerabilidad social que enfrentan innumerables estudiantes.

Palabras clave: Herramientas tecnológicas; Formularios de Google; Salud mental; Vulnerabilidad social.

\section{Introdução}

Atualmente, o processo de ensino e aprendizagem apresentou avanços significativos, principalmente, no que se refere ao ensino remoto, devido à pandemia da covid-19 (Dias et al, 2020).

A proibição do contato entre pessoas através de aglomerações, seja em sala de aula, reuniões ou outra forma de união, estimulou muitos docentes a buscarem novas formas de ensinar e aprender por meio de ferramentas tecnológicas (Dias et al, 2020),

Monteiro e Santos (2019), afirmam que as tecnologias têm impactado a educação de tal forma que têm mudado a sua forma de concepção, demandando um novo olhar para as metodologias, estratégias e, inclusive, o modo de se comunicar.

Nos últimos anos, as tecnologias estão sendo utilizadas para melhorar o desempenho dos alunos e o processo de trabalho docente, dentre os quais destacam-se as formas como são realizadas as avaliações do ensino. 
É válido ressaltar que a avaliação não pode ser usada como instrumento reducionista, voltado à aplicação de meios para a coleta de dados. O conceito de avaliação deve ser um componente do processo educativo, que tem como finalidade orientar todo o processo de ensino e aprendizagem.

Nesse contexto, diversas ferramentas tecnológicas estão sendo implementadas na educação básica em tempos de pandemia da covid-19. Dentre essas ferramentas, podemos destacar, o Google sala de aula, Google forms, Zoom, Meet, Teams e muitas outras que permitem interação entre mais de 30 participantes simultaneamente, de forma gratuita (Mota, 2019).

Essas novas tecnologias abrangem uma variedade muito grande de ferramentas, dentre as quais se destaca o Google Forms, que é o objeto deste trabalho.

Dentre os problemas que se observaram foi a conexão, o nível de internet de cada usuário e a falha de comunicação, observada principalmente nos lugares mais distantes onde a internet e o acesso é mais difícil, o local não possui um acesso razoável, o sinal emitido pelas operadoras de telefonia tem dificuldade de se chegar e com isso a internet não funciona de uma forma razoável em muitas localidades.

De acordo com Deslandes e Coutinho (2020), há milhões de pessoas no mundo inteiro que se viram obrigadas a interromper bruscamente boa parte das interações humanas face a face (presenciais). De uma hora para a outra a transmissão de dados por meio digital, genericamente chamada de Internet, tornou-se o único meio disponível para a não interrupção completa das interações sociais e de trabalho. Nesse sentido o isolamento social foi um dos causadores e do efeito multiplicador desse "boom" tanto no ensino remoto quanto na utilização da internet em inúmeras atividades educacionais ou não.

Face ao exposto, o objetivo do presente estudo é descrever a utilização da ferramenta google forms como instrumento de avaliação com alunos da educação básica em tempos de pandemia da covid-19.

Temos diversas formas de ensinar e aprender em múltiplos espaços e a todo momento, a educação sempre combinou vários espaços, tempos, atividade, metodologias, públicos, ou seja, a educação sempre foi misturada, e esse processo ficou mais evidente com a conectividade.

Moran (2015), afirma que Híbrido significa misturado, e que tudo pode ser misturado, combinado, e podemos com os mesmos "ingredientes" montar diversos "pratos".

Com a pandemia as escolas e professores procuram forma de levar a educação para os alunos, e a tecnologia tornou-se um meio para levar o ensino para os discentes.

Será que o ensino Híbrido se resume em apenas no uso da tecnologia?

Na educação acontecem vários tipos de mistura, blended ou educação hibrida: de saberes e valores, quando integramos várias áreas de conhecimento (no modelo disciplinar ou não); de metodologias, com desafios, atividades, projetos, games, grupais e individuais, colaborativos e personalizados. Também falamos de tecnologias hibridas, que integram as atividades da sala de aula com as digitais, as presenciais com as virtuais. Hibrido também pode ser um currículo mais flexível, que planeje o que é básico e fundamental para todos e que permita, ao mesmo tempo, caminhos personalizados para atender às necessidades de cada aluno. (Moran 2015, pp. 28)

O ensino Híbrido não fica restrito apenas ao uso de tecnologia em sala de aula, nesse momento de pandemia, e com o isolamento social, muitas escolas e professores gravam as aulas ou até mesmo a aula é transmitida ao vivo pelas escolas para os alunos ele também é a articulação de processos de ensino e aprendizagem mais formais com aqueles informais, de educação aberta e em rede. Implica misturar e integrar áreas, profissionais e alunos diferentes, em espaços e tempos distintos. (Moran, 2015. pp. 29).

Nesse momento de isolamento social o afeto e a colaboração entre alunos e professores, é uma forma de motivar a todos a continuar o processo de ensino e aprendizagem. A comunicação afetiva, com o apoio das tecnologias, nos ajuda a 
aprender a partir das histórias de vida e dos sonhos de cada um dos alunos. O clima de acolhimento, confiança, incentivo e colaboração é decisivo para uma aprendizagem significativa e transformadora.

Dentre as inúmeras formas utilizadas no ensino durante a pandemia foi o formulário google, onde admite uma infinidade de maneiras de avaliação e envio aos alunos, onde basta se ter um celular, Android ou IOS, para que se possa responder provas, trabalhos, testes ou mesmo uma forma de informação e de divulgação.

$\mathrm{O}$ fechamento das escolas teve consequências pesadas na sociedade brasileira, principalmente no comportamento dos jovens e dos adultos que os acompanham em casa.

No atual contexto de fechamento provisório de escolas, em que alunos estarão sem aulas presenciais, há grande preocupação sobre uma possível paralisação completa do processo de ensino-aprendizagem e de redução dos estímulos que busquem o desenvolvimento cognitivo e socioemocional dos alunos. Neste caso, e especialmente considerando os Ensinos Fundamental e Médio, estratégias que incentivem e apoiem atividades a distância se tornam essenciais para reduzir os potenciais efeitos da crise na Educação (Brasil, 2020).

A partir do início da pandemia, dentre os meses de março e abril de 2020, houve muita indecisão no que e como fazer a educação, pois ela é pautada no geral em turmas que no geral tem de 25 alunos ou mais em sua maioria. Já no final de abril, as escolas já começaram a adotar e migrar para o ensino remoto quase em sua totalidade (Dias, G. N. et al, 2020).

O trabalho realizado dentro de casa sofre inúmeras variações e interferências de elementos externos muitas vezes imprevisíveis, que no cotidiano escolar não ocorrem. Não há como saber se seu aluno está realmente presente te ouvindo e fazendo as atividades que lhe foram solicitadas. As aulas por plataforma não garantem essa postura do aluno de uma forma igualitária com a presencial.

A forma de como se avaliar foi alterada de uma maneira impensável. Antes de pensar em avaliar temos que listar uma série de situações que poderão acontecer durante a aplicação deste instrumento, como também qual o objetivo almejado com estes exames, nesta corrente, (Monteiro \& Santos, 2019), afirmam:

É importante observar que a avaliação não pode ser usada como instrumento reducionista, como se avaliar pudesse simplesmente limitar-se à aplicação de meios para a coleta de dados. O conceito de avaliar deve ser um componente do processo educativo, que tem como finalidade orientar todo o processo de ensino. Frente ao exposto, pensar em desenvolver uma nova postura avaliativa requer desconstruir e reconstruir a concepção e a prática de avaliação. Isto remete a uma reflexão em torno de algumas questões básicas que constituem a compreensão epistemológica e pedagógica do conceber e do fazer avaliativo. Tais questões estão associadas com: Para que avaliar? O que avaliar? Quando avaliar? Como avaliar e o que fazer com os resultados da avaliação? O domínio dessas perguntas contribui para promover mudanças consistentes, sistemáticas e intencionais nas formas de avaliar (Monteiro \& Santos, 2019).

\section{Metodologia}

Trata-se de um estudo descritivo, transversal, realizado com alunos do ensino médio de uma escola pública, da cidade de Belém do Pará, frente à utilização do Google forms, como instrumento do processo avaliativo de ensino e aprendizagem. Foi utilizado o manual metodológico de (Pereira et al., 2018).

A população do estudo foi composta por 105 alunos do ensino médio, sendo em média 26 por turma. Os critérios de inclusão foram: ser aluno do ensino médio; matriculados da escola investigada; estar cursando as disciplinas de Língua Portuguesa, Física, Matemática, Biologia, História e Geografia, no segundo semestre de 2020. Foram excluídos todos aqueles que não atenderam aos critérios de inclusão e indivíduos que se recusaram participar da pesquisa.

O estudo teve a duração de cinco meses, com início em 01 de abril de 2020 até 15 de janeiro de 2021. 
A técnica utilizada na coleta de dados foi à aplicação do formulário Google forms, nas duas últimas provas relativas ao $4^{\circ}$ bimestre, visando avaliar a evolução de conhecimento referente aos conteúdos ministrados em cada disciplina. Foram realizadas 2 avaliações de cada disciplina, tendo como média 10 questões objetivas, com duração de 2 horas.

Os resultados obtidos foram analisados com base em estatística descritiva do desempenho dos alunos em cada disciplina. Os dados foram processados para o software Excel da Microsoft ${ }^{\circledR}$ versão 2016 e discutidos mediante literatura atualizada.

Participaram do estudo 105 discentes estratificados por sexo e faixa etária. Destes, 59\% eram do sexo feminino e $41 \%$ do sexo masculino, com idade variando entre 15-19 anos.

Ao todo foram realizadas em média 9 aulas on line, por disciplina, com participação de $95 \%$ discentes em cada aula. As aulas iniciavam com os docentes abordando os temas do dia e, a partir do conhecimento prévio dos discentes, questionamentos e discussões eram realizados, assim as atividades passavam a ser participativas.

As avaliações eram realizadas sempre uma vez por mês, com auxílio do Google forms. A preocupação era que esta avaliação possuísse 10 questões de grau extremamente difícil, semelhante às questões de vestibulares mais concorridos do país. O tempo de prova era de $2 \mathrm{hs}$ e, não foi concedido nenhum tempo extra, após 40 minutos de início $80 \%$ dos participantes, já haviam finalizado o envio do formulário do Google Forms com as respostas da prova.

\section{Problemas e Diversidades Encontrados Durante a Pandemia, com Reflexos na Educação.}

Dentre os problemas enfrentados por todos é o problema da Saúde Mental, dos indivíduos submetidos ao isolamento, principalmente da faixa etária dos 6 aos 21 anos, que na maioria é a população das escolas públicas, particulares e as Universidades. Percebemos que este público no geral chegava a se afastar de casa em média de 5 a 8 horas, dependendo da escola ou instituição que frequenta e do lugar que reside. Houve uma mudança considerável do cotidiano destes sujeitos que trouxe consequências a saúde mental de muitos.

Nesse cenário, durante uma pandemia, o medo intensifica os níveis de estresse e ansiedade em pessoas saudáveis e aumenta os sintomas daquelas com transtornos mentais preexistentes Ramírez-Ortiz et al. (2020). Pacientes diagnosticados com COVID-19 ou com suspeita de infecção podem experienciar emoções intensas e reações comportamentais, além, da culpa, medo, melancolia, raiva, solidão, ansiedade, insônia etc. Estes estados podem evoluir para transtornos como ataques de pânico, Transtorno de Estresse Pós-Traumático (TEPT), sintomas psicóticos, depressão e suicídio. Sobretudo preponderantes em pacientes em IS, no qual o estresse tende a ser o mais prevalente (Shigemura et al., 2020); (Brooks et al., 2020).

Kentish-Barnes et al. (2015), pontuam que se deve estar atento para outros fatores de risco, sendo tais, baixa autoestima, diagnóstico prévio de distúrbio mental, baixo poder aquisitivo, falta de suporte social e condições dignas de trabalho. Assim, todos estes fatores podem influenciar significativamente o grau de vulnerabilidade do indivíduo no âmbito psicossocial (Xiang et al., 2020).

O uso excessivo de celulares e computadores pode causar dependência, principalmente no que se diz ao conteúdo de jogos, on line ou não, baixados os programas já prontos para jogar, muitos de acesso gratuitos e com uma performance por vezes até profissional, acaba distanciando os jovens das tarefas e atividades antigas para as particularidades novas criadas por esses aplicativos de jogos, normalmente instalados no celular do indivíduo.

Na perspectiva do ensino o efeito da Pandemia e suas restrições teve efeito catastrófico (Santo \& Moura, 2020); (Lima et al., 2021). Quando se fala em isolamento social, percebemos que o ambiente mais afetado foi o ramo educacional, justamente pelas suas características em que as escolas no geral têm em torno de 30 alunos em sala, ocasionando uma 
aglomeração natural na maioria dos casos. Ainda temos escolas que possuem mais alunos por sala como 40, 50 chegando em cursinhos preparatórios a se ter até 300 alunos em uma única sala.

Toda essa estrutura foi suspensa já no início da Pandemia em abril de 2020. O retorno ainda não ocorreu de uma forma efetiva. Tivemos algumas escolas que retornaram em novembro de 2020 com uma forma discreta, chamado de ensino Híbrido, ou seja, uma parte presencial outra on line e revezamento de alunos para diminuir o quantitativo por sala (Mill \& Santiago, 2021).

Naturalmente se a sala de aula for relativamente grande e tenha condições para se manter o distanciamento de 1,5 metros a escala poderá ser otimizada, partindo do princípio que metade da turma de 30 alunos teriam aulas nos dias pares e a outra metade nos dias ímpares, favorecendo dessa forma o ensino mas tomando todos os cuidados necessários. Em uma escola que só funcione em um turno e possuir salas de aulas relativamente grandes, a rotina pode melhorar dividindo metade da turma no período da manhã e a outra metade no período da tarde, sendo respeitado os compromissos individuais dos alunos nessa divisão. (Dias et al., 2020).

Outros problemas decorrentes da Pandemia vieram à tona, como o uso excessivo da internet, por estar em isolamento e ter necessidade de ter contato social e o sentimento de "não poder". Seus amigos e colegas agora estão longe, seus parentes, até os mais próximos também estão distantes, criando dessa forma uma expectativa e ansiosidade neste indivíduo que antes não se sabia da existência dessa problemática.

Na pretensão de ser amado, apreciado e aplaudido, os indivíduos estariam submetidos ao que chamou de "tiranias da visibilidade", tendo que estilizar e cultivar suas imagens aos moldes de personagens da mídia audiovisual e "atuar como se estivesse sempre diante de uma câmera, disposto a se exibir em qualquer tela" (Sibila, 2008).

O combate da pandemia de Covid-19 obrigou o homem a descobrir sentido dentro de si mesmo. Enquanto os espaços públicos ficaram vazios, as mentes se encheram. Habituar-se isolado, não faz parte da natureza humana, a qual necessita de afeição, aproximação e diálogo para se manter em balanceamento. Esta doença fez com que o indivíduo enxergasse a majestade de significados dentro de ínfimas ações. Templos foram fisicamente fechados, porém, milhares de outros se abriram, dentro de cada residência, em cada demonstração de empatia e alteridade. $\mathrm{O}$ abraço tornou-se proibido, enquanto as redes sociais passaram a ser entediantes. Aspirações e desígnios tiveram que ser temporariamente suspensos para proteger aquilo que há de mais valioso: a vida. O ser humano teve que aprender a coexistir com seus próprios fantasmas, sem ter para onde fugir, teve que aprender a lidar com suas frustações e receios.

Problema recorrente enfrentado por grande parte da população brasileira foi o não acesso, não ter como acessar as plataformas digitais ou qualquer recurso possível disponibilizado a sua antiga turma de sala de aula, por um motivo comum e que atingiu a milhares de estudantes: o acesso a internet. Sente este último o principal motivo. Muitos tem aparelho celular de modelo android ou IOS, mas não tem acesso nem pacote de dados móveis disponíveis, pois não tem condições de manter um conta fixa de internet para poder assistir aulas online e nem receber e-mails ou mensagens de grupo.

Esta pandemia tem evidenciado a desigualdade que demarca nossa sociedade, pois, enquanto algumas crianças têm acesso à tecnologias de ponta, possuem acesso ilimitado à internet e recebem em casa o apoio dos pais/responsáveis, tantas outras ficam à margem deste processo, seja pela falta de equipamento tecnológico adequado em casa, seja pelo fato de os responsáveis dedicarem-se à outras preocupações, seja por estes não terem a formação escolar adequada para orientá-los em relação à realização das atividades ou, ainda, por situações de extrema pobreza e vulnerabilidade social (Vieira, \& Ricci, 2020). 
Diante das diferenças e todas as situações e problemas em que a sociedade se encontrou, no retorno presencial é indispensável que as escolas repensem todo o processo educativo realizado durante a pandemia, principalmente à aprendizagem dos alunos e os resultados das avaliações feitas e utilizadas como parâmetro finalizar e progredir os alunos.

Será necessário analisar de uma forma qualitativa e individual o suporte dados aos alunos pelos pais durante a pandemia. Se esse auxílio dados pelos pais foi suficiente e um problema ainda maior o fato de muitas crianças não ter qualquer tipo de ajuda ou auxílio de pais ou responsáveis, por estarem nesse momento isolados e os pais ou responsáveis trabalhando em outro local.

é imprescindível também que seja atribuído maior enfoque ao acolhimento destas crianças e jovens, destinando-os um olhar atento, que nos possibilite estar sensíveis à identificação não só dos prejuízos escolares, mas de possíveis situações de violência física e sexual, bem como questões de prejuízo da saúde mental. Em resumo, a desigualdade e vulnerabilidade, já visível, e muitas vezes ignorada, na escola presencial, foi fortemente acentuada com a pandemia (Santos, 2020).

A vulnerabilidade social enfrentada por vários alunos, por diversas formas perpassa até por violência física e sexual, onde problemas decorrentes do isolamento e saúde mental de todos os componentes da família, decorrentes de situações adversas, como ausência de alimentos(fome) e espaço de convívio extremamente reduzido, algumas famílias residem em favelas e barracos em que o espaço se reduz muitas vezes a $15 \mathrm{~m}^{2}$, não se tendo nem um banheiro para a família, sendo compartilhado por outras pessoas, todos esses problemas estruturais são agravados ainda pela falta de engajamentos dos responsáveis pela criança em orientar e fiscalizar a realização das atividades propostas online, quando se tem esse recurso disponível.

Todas esses problemas que já coexistiam antes da Pandemia foram agravados fortemente, devido ao isolamento social, onde ficar num cubículo durante várias horas e durante muitos meses, sem a estrutura necessária, agravou a saúde mental de todos nessa unidade familiar.

A falta da escola no sentido presencial significou uma perda muito grande e incomparável em distintas situações, onde todos sentiram a sua falta. Nesse aspecto, a escola,

é espaço de atuação autônoma e coletiva, de vivências e interação, de relacionamento com o outro de forma física, presencial e humana, mas também uma instância onde as tecnologias podem e devem cumprir o importante papel de apoio dos processos de ensino e de aprendizagem. Isso porque o processo de aprendizagem é coletivo, conta com a curiosidade mútua, com a liberdade e interação que as crianças precisam ter para aprender. A escola é muito mais do que aprender por si mesmo! Transcende a posição de espaço de aprendizagem: é uma comunidade onde os professores e alunos relacionam-se, interagem e aprendem mutuamente, por meio do contato pessoal, das experiências vivenciadas no coletivo, das confidências, do relacionamento. É fato que as crianças que têm bom relacionamento na escola, na sala de aula, inevitavelmente, aprendem melhor. Os professores sabem disso, e agora, isto está sendo comprovado por esta crise pandêmica. (Tricate, 2020).

A escola de fato é espaço para muitos, de várias formas possíveis. Quando pensamos em escola nos lembramos que existem classes e mais classes. As de 20 alunos, as de 30, 40 ou até 100 alunos, dependendo da escola. Todos aglomerados em uma sala de aula, distantes entre si com um espaço menor que $60 \mathrm{~cm}$, ouvindo, assistindo e resolvendo exercícios de um único professor que tem por finalidade conduzir um conteúdo específico de um programa previamente determinado chamado de currículo escolar. Enfim esse formato, existe há mais de 500 anos, e o que mudaram foi somente o currículo nas diversas localidades em que esses alunos residem no nosso mundo global.

$\mathrm{O}$ que temos que refletir e o que nos balançou, foi que essa estrutura que funcionou por mais de 500 anos, agora funciona de uma forma totalmente diferente, com o professor distante em outra casa, outra cidade ou até outro país, da mesma 
forma meus colegas e todos os participantes dessa escola em sua casa sozinhos. A escola física, deixou de existir. Os jogos de futebol, vôlei, voleibol, basquetebol, deixaram de existir coletivamente nas escolas. Os intervalos de aula em que as crianças interagem umas com as outras, a cantina em que os alunos esperam um dia após o outro para provar os lanches que não comem em casa. Tudo isso acabou, pelo menos temporariamente.

A principal mudança é que nesse novo formato a escola não é para todos. Só funciona para aqueles que conseguem ter um equipamento, celular ou computador com internet para receber o sinal com qualidade. Desta forma temos que repensar a educação a estes alunos que não tem condições financeiras como também não possuem a ajuda de um familiar que o acompanhe, principalmente no caso do ensino fundamental menor, com crianças de 6 a 10 anos de idade.

\section{Resultados e Discussão}

A utilização dos formulários do Google Forms facilitou em todos os sentidos as avaliações feitas remotamente, pois o proprietário do formulário pode controlar o horário da entrega e já pode receber corrigido, bastando lançar as notas dos alunos na caderneta ou no sistema da escola. Também muito utilizado nas universidades públicas ou particulares.

O mais utilizado foi o de forma objetiva, uma vez que o formulário google oferece a opção de autocorreção automática de todos os sujeitos endereçados, facilitando a vida do professor. Inclusive a divulgação das notas também de uma maneira automática logo após a entrega ou ao comando do dono do formulário (Professor ou responsável pela turma).

Uma vantagem do formulário google é que o proprietário (quem está editando e fazendo), não precisa digitar. Pode-se simplesmente colar prints de questões ou figuras para construção do questionário, facilitando e otimizando a sua elaboração em pouco tempo.

Para Heidemann e Oliveira (2010), o Google Drive é considerado uma "evolução natural" do Google Docs. Tal plataforma congrega o Google Forms e mais um leque de aplicativos de produtividade, que oferecem a edição de documentos, folhas de cálculo, apresentações e muito mais. Dentre esses aplicativos, encontram-se o Google Documents, o Google Spreadsheets, o Google Presentations e o Google Drawings.

A ferramenta do Google Forms possibilita personalizar os questionários com cores, criar diversos tipos de perguntas, como de múltipla escolha, caixas de checagem, escalas, listas suspensas, etc., usar vídeos e imagens para ilustrar e deixar as perguntas que estão sendo feitas mais claras, fazer uso de diversos templates prontos do Google Forms, acessar os questionários do Google Forms em smartphones e tablets, seja para responder ou criar seus questionários. Em suas funcionalidades, destacam-se o tempo no processo de coleta e análise de dados e a manipulação de enormes pilhas de documentos.

Também existe a vantagem do link a ser compartilhado funcionar em qualquer equipamento IOS ou Android, mesmo os antigos, podendo ser respondido pelo celular, computador, tablet e até TVs novas com compartilhamento de internet.

O professor pode deixar de aceitar as respostas quando quiser. Se a prova tem duas horas de duração, basta ir ao formulário e não aceitar mais respostas e assim o sujeito envolvido não consegue enviar e não consegue abrir o link.

Para baixar todas as respostas o dono do formulário, consegue fazer o download em Excel, podendo organizar em ordem alfabética, para ter o controle total de todas as notas.

A questão da confiabilidade e do crédito do conhecimento do aluno foi levada a importância da prova com consulta. Ou seja, o fato de o sujeito estar respondendo a prova enviada pelo formulário google, estar consultando ou não, teve importância secundária no ensino remoto onde se visava a resposta do aluno, mesmo consultando ainda assim ocorre o aprendizado (Mota, 2019). 
Essas são as inúmeras vantagens do formulário google, porém existe uma enorme e gigantesca desvantagem em comparação coma as provas tradicionais: no formulário google estão sendo usados o ensino é na forma remota ou híbrida, onde o aluno responde em casa com todo o aparato de consultas possíveis, muitas vezes conectados à internet para pesquisa ou ao próprio grupo da sua turma onde uma prova de 10 questões fica dividida para 40 alunos compartilhando entre eles as possíveis soluções, isso tem levado ao acerto com média em torno de 70 a $80 \%$ muito diferente da média obtida antes da pandemia onde as provas eram presenciais e sem consulta.

O estudo constatou que 75\% alunos obtiveram notas acima de 8,0 em uma prova extremamente difícil e de conteúdo geral referente aos componentes curriculares: Biologia, História, Geografia, Língua Portuguesa, Física e Matemática, conforme podemos observar na Figura 1.

Observando o gráfico da figura 01 , temos o desempenho geral das três turmas do $3^{\circ}$ ano no ano de 2020 , fica em torno de $70 \%$ de rendimento geral, com poucos alunos que apresentam comportamento abaixo de $60 \%$, o que demonstra o alto índice de desempenho dos alunos dessa escola pública em Belém (PA).

Qual o aprendizado que o aluno está obtendo em face das consultas e obtenção por terceiros das respostas indagadas no formulário prova?

Este é um questionamento que só saberemos após o término da pandemia e que todas as atividades educacionais voltarem ao normal.

Calculando os desempenhos obtidos acima da nota 7,0 percebemos que o quantitativos de alunos beneficiados com esse rendimento foram: Biologia 73\%, História 78\%; Geografia 81\%; Língua Portuguesa 80\%; Física 68\%; Matemática 69\%, todas as componentes curriculares citadas com rendimento percentual consideravelmente alto acima da nota 7,0.

Pelo gráfico da figura 1 , os rendimentos são parecidos mais não totalmente iguais. Observa-se que nas disciplinas de Física e Matemática há uma queda considerável no desempenho dos alunos. A componente curricular Física apresentou um total de $67 \%$ dos sujeitos da pesquisa obtiveram notas entre 8 e 9 , e um percentual de $28,5 \%$ com desempenho regular variando as notas de 5 a 7 pontos respectivamente. Provavelmente o nível das questões influiu nos resultados, pois tratava-se de um questionário adaptados aos itens do ENEM e similar às questões do exame intelectual de entrada às Escolas Militares. Com Índices muito próximos, observam-se o mesmo desempenho em relação a componente curricular Matemática.

O que causa muita estranheza é que Conforme a Avaliação do (Fórum Econômico Mundial, 2016) a educação em Matemática no Brasil é uma das piores no Mundo. Entre 139 países avaliados o Brasil ocupa a 133a colocação. Em 2014, menos de $6 \%$ dos alunos brasileiros se encontravam em nível adequado de aprendizado, isto é, grande parte dos alunos eram analfabetos funcionais e não conseguiam racionar nem interpretar dados simples (SAEB, 2018). Por isso, hoje nosso país é um dos dez países com maior número de estudantes com baixo rendimento escolar em Matemática e Física (PISA, 2018).

Em contrapartida, nestes exames de $4^{\text {a }}$ Bimestral, todas as componentes curriculares o desempenho Insuficiente, de 0 a 4 pontos é praticamente inexistente em todas as componentes curriculares, praticamente desprezível. Menos que 5\% dos alunos desta pesquisa se enquadraram neste item. 
Figura 1: Gráfico demonstrativo de desempenho de 3 turmas do $3^{\circ}$ ano do ensino médio, total de 105 alunos, referentes aos componentes curriculares: Biologia, História e Geografia, Língua Portuguesa, Física e Matemática na última avaliação de 2020 de uma escola pública da cidade de Belém (PA).

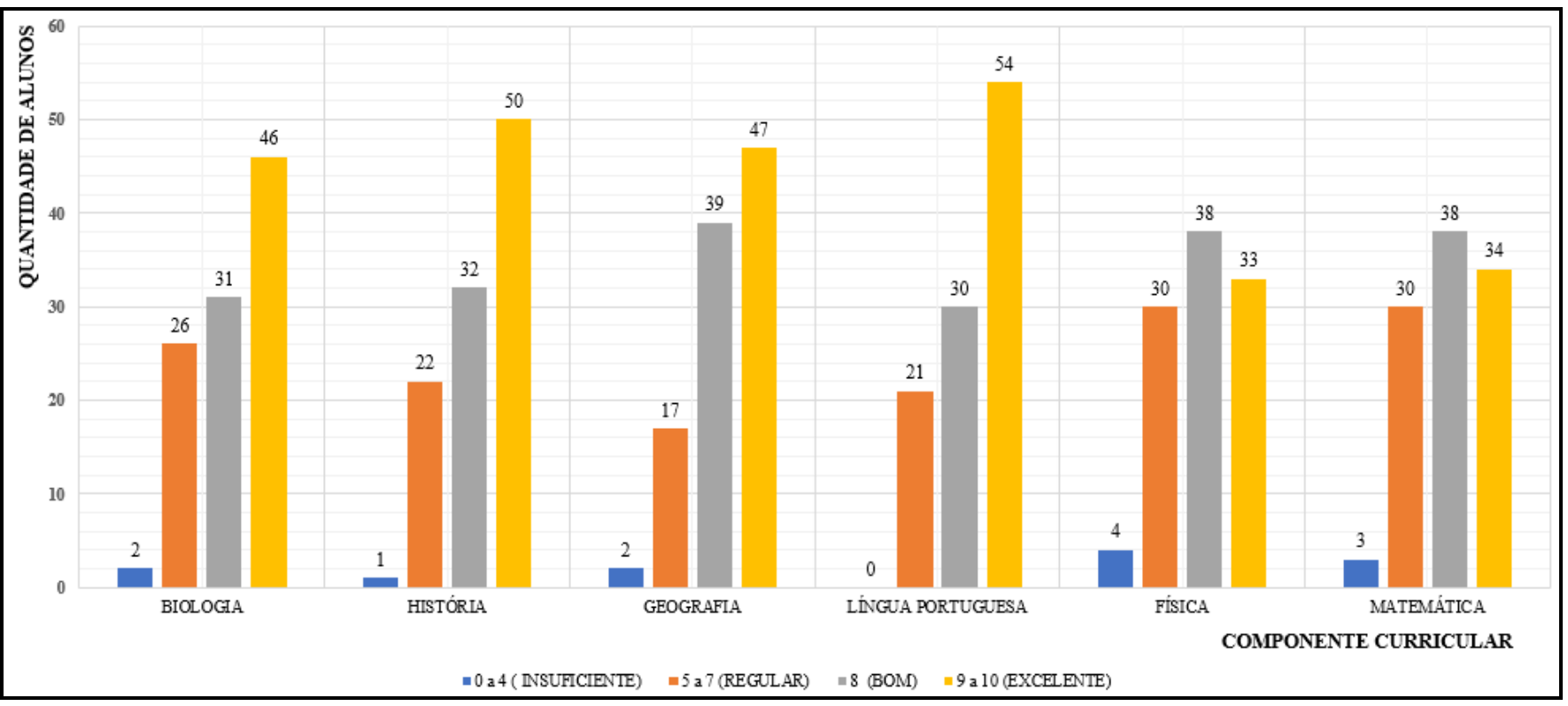

Fonte: Dados da Pesquisa.

A ferramenta do Google Forms, que permite realizar testes e provas com tempo regulamentado e liberado pelo professor mostrou-se muito eficiente e nos trouxe uma nova forma de avaliar. Inúmeros problemas foram levantados como a credibilidade do rendimento dos sujeitos envolvidos nesta pesquisa, mas na atual conjuntura de Pandemia, não nos foi oferecida outra forma de avaliar mais efetiva e exata que a ferramenta do google forms.

\section{Considerações Finais}

Nesta pesquisa, investigamos as tendências veiculadas a respeito da COVID-19, no meio educacional, social e a saúde mental da sociedade envolvida na Pandemia, o que nos levou a ter conhecimento do avanço da pandemia no Brasil além dos inúmeros efeitos decorrentes, nos possibilitando traçar estratégias para tecer uma possível conclusão para o momento em que vivemos, com a explosão de casos a mercê da chegada da vacina em pequenos grupos prioritários.

As novas ideias e a aplicação dos recursos tecnológicos permitiram uma reformulação e a melhoria de determinadas ações do ensino, os quais são fomentadores dos desafios da educação frente a pandemia. O processo flexível, aberta, híbrida e integrada foram importantes a superação, aprendizado, saber e a satisfação dos envolvidos: alunos, docentes e outros.

A utilização dos formulários google facilitou em todos os sentido as avaliações feitas remotamente, pois o proprietário do formulário pode controlar o horário da entrega e já pode receber corrigido, bastando lançar as notas dos alunos na caderneta ou no sistema da escola. Também muito utilizado nas universidades públicas ou particulares.

Com relação ao uso dos formulários foram encontradas inconsistências com relação aos resultados das avaliações em várias componentes curriculares, onde o desempenho médio ficou acima dos 75\%, mostrando um resultado significativamente maior ao normalmente obtido nas aulas presenciais onde o desempenho das componentes curriculares Matemática e Física são baixos (Dantas Filho, 2017). 
Conforme as medidas restritivas foram sendo instauradas e o uso de ferramentas tecnologias foram se solidificando, principalmente na composição de um novo plano de ensino, pautado em materiais didáticos, formação das turmas, matrícula dos alunos, processos logísticos, encontros online e outros.

Inúmeros fatos aconteceram e estão ocorrendo ainda na Pandemia atual em que vivemos. Estamos certos de que existe um abismo intransponível com as relações sociais que possuíamos antes e agora com o isolamento social. Deixamos de nos relacionar com amigos e colegas presencialmente, e agora só temos a nossa família de convívio diário. Muitas das relações interpessoais com o tempo foram deixadas de lado por diversos fatores, o principal é que a nossa rotina mudou completamente do que era antes. Provavelmente seja um tempo que vai passar, as vacinas já chegaram e aos poucos, num breve espaço de tempo, iremos voltando ao normal com a erradicação da Pandemia nos próximos anos.

\section{Referências}

Brasil. (2020). Nota técnica: Ensino a distância Educação Básica frente à pandemia da Covid-19”, de Todos Pela Educação. Análise e visão do Todos Pela Educação sobre a adoção de estratégias de ensino remoto frente ao cenário de suspensão provisória das aulas presenciais.

Brooks, S. K., Webster, R. K., Smith, L. E., Woodland, L., Wessely, S., Greenberg, N., \& Rubin, G. J. (2020). The psychological impact of quarantine and how to reduce it: rapid review of the evidence. Lancet Infect Dis, 395(10227), 912-920. https://doi.org/10.1016/S0140-6736(20)30460-8.

Deslandes S. F. \& Coutinho T.(2020). O uso intensivo da internet por crianças e adolescentes no contexto da Covid-19 e os riscos para violências autoinflingidas. Instituto Fernandes Figueira, Fiocruz.

Dantas Filho, J. V. (2017). EDUCA - Revista Multidisciplinar em Educação, 4(9), 98 a 113.

Dias G. N., Vogado G. E. V., Barreto W. D. L., et al. (2020). Retorno às aulas presenciais no sistema educacional do estado do Pará Brasil: Obstáculos e desafios durante a epidemia de Covid-19(Sars-Cov-2) Braz. J. of Develop., 6(6), 37906-37924.

Fórum Econômico Mundial (2016). Avaliação da Educação em Matemática no Brasil. Global Information Technology.

Heidemann, L. A. \& Oliveira, A. M. M.(2010). Ferramentas online no ensino de ciências: uma proposta com o Google Docs. Física na Escola, 111(2).

Kentish-BarneS, N., Chaize, M., Seegers, V., Legriel, S., Cariou, A., Jaber, S., Lefrant, J. Y., Floccard, B., Renault, A., Vinatier, I., Mathonnet, A., Reuter, D., Guisset, O., Cohen-Solal, Z., Cracco, C., Seguin, A., Durand-Gasselin, J., Éon, B., Thirion, M., \& Azoulay, E.(2015). Complicated grief after death of a relative in the intensive care unit. EUR RESPIR J, 45(5), 1341-1352. https://doi.org/10.1183/09031936.00160014.

Lima, D. da C. B. P., Rodrigues, M. C. N., \& Cruz, J. R. (2021). Educação Semipresencial e Híbrida no Brasil: descortinando conceitos e regulamentação. Revista Educaonline. 15(1).

Monteiro, R. L. S. G. \& Santos, D. S. (2019). A utilização da ferramenta Google Forms como instrumento de avaliação do ensino na Escola Superior de Guerra.Revista carioca de Ciência, Tecnologia e Educação (on line). 4(2).

Moran, J. (2015). Educação híbrida: Um conceito-chave para a educação, hoje. Lilian, B., Adolfo, T. N. \& Fernando, de M. T. Ensino Híbrido: Personalização e tecnologia na educação. [Ensino Híbrido: Personalização e Tecnologia na Educação.] Penso.

Mota, J. S.(2019). Utilização do google forms na pesquisa acadêmica. Revista Humanidades e Inovação 6(120.

Pereira, A. S., et al. (2018). Metodologia da pesquisa científica. UFSM.

Programa Internacional de Avaliação de Alunos (2018). Classificação de Desempenho Escolar em Matemática e Física. PISA.

Ramírez-Ortiz, J., Castro-Quintero, D., Lerma-Córdoba, C., Yela-Ceballos, F., Escobar \& Córdoba, F.(2020). Consecuencias de la pandemia COVID-19 en la Salud Mental asociadas al aislamiento social. SciELO Preprints, 1, 1-21. https://doi.org/10.1590/SCIELOPREPRINTS.303.

Santo, S. A. C. \& Moura, G. C. S.(2020). O uso da tecnologia na educação: Perspectivas e entraves. Revista Científica Multidisciplinar Núcleo do Conhecimento. 4, 31-45.

Santos, B. S. (2020). A Cruel Pedagogia do Vírus. Edições Almedina, S. A. Portugal.

Shigemura, J., Ursano, R. J., Morganstein, J. C., Kurosawa, M., \& Benedek, D. M. (2020). Public responses to the novel 2019 coronavirus (2019-nCoV) in Japan: Mental health consequences and target populations. Psychiatry and Clinical Neurosciences, 74(4), 281-282. https://doi.org/10.1111/pcn.12988.

Sistema Nacional de Avaliação da Educação Básica - SAEB (2018). Resultados do SAEB-2017.

Sibilia P. (2008). O show do eu: a intimidade como espetáculo. Nova Fronteira.

Tricate, M. (2020). A educação a distância contra a pandemia. PEA UNESCO, https://revistaeducacao.com.br/2020/03/25/educacao-a-distancia-unesco/. 
Research, Society and Development, v. 10, n. 4, e44910414180, 2021

(CC BY 4.0) | ISSN 2525-3409 | DOI: http://dx.doi.org/10.33448/rsd-v10i4.14180

Vieira, L., Ricci M.C. C. (2020). A educação em tempos de pandemia: soluções emergenciais pelo mundo. Observatório do ensino médio em Santa Catarina, Brasil. Editorial, Abril.

Xiang, Y. T., Yang, Y., LI, W., Zhang, L., Zhang, Q., Cheung, T., \& NG, C. H. (2020). Timely mental health care for the 2019 novel coronavirus outbreak is urgently needed. Lancet Psychiatry, 7(3), 228-229. https://doi.org/10.1016/S2215-0366(20)30046-8. 